\title{
Pengalihan peran sementara pengasuhan anak dari orang tua ke nenek dan kakek
}

\author{
Temporary role for children caring from parents to grandmother and \\ grandfather
}

\author{
Muhammad Rizky Afif Zakaria \\ Departemen Sosiologi, Fakultas Ilmu Sosial dan Ilmu Politik, Universitas Airlangga \\ Surabaya, 60286, Jawa Timur, Indonesia \\ E-mail: m.rizky.afif.zakaria-2014@ fisip.unair.ac.id
}

\begin{abstract}
Abstrak
Pola asuh adalah sekelompok sikap orang tua yang berkomunikasi dengan anak-anak mereka yang menciptakan suasana emosional di mana perilaku pengasuhan diungkapkan. Peran aktif orang tua adalah upaya langsung terhadap anak-anak dan peran penting lainnya dalam menciptakan lingkungan sosial pertama oleh anak-anak bukan untuk nenek dan kakek. Studi ini berfokus pada mentransfer peran sementara pengasuhan anak dari orang tua ke nenek dan kakek dan bagaimana kakek nenek merawat anak di antara ibu yang bekerja. Penelitian ini menggunakan teori aksi sosial dari teori pengasuhan Max Weber dan Baumrind. Metode penelitian yang digunakan adalah kualitatif, informan dalam penelitian ini adalah sembilan belas anggota keluarga dengan latar belakang keluarga yang berbeda. Lokasi penelitian dilakukan dalam keluarga yang mentransfer peran pengasuhan kepada nenek dan kakek di kota Surabaya. Teknik penentuan informan menggunakan teknik bola salju. Metode pengumpulan data dalam penelitian ini dengan wawancara mendalam dan berpartisipasi langsung di lapangan. Hasil yang ditemukan dalam penelitian ini adalah sembilan belas informan berdasarkan bagaimana proses mentransfer peran pengasuhan anak dari orang tua ke kakek-nenek. Melihat faktor pengasuhan yang bergeser, orang tua yang sibuk bekerja, pengasuhan anak oleh kakek-nenek hingga cucu mereka kurang asertif dan selalu menaati keinginan cucunya, kematian orang tua, ditemukannya orang tua dan munculnya trauma bagi perawatan orang lain yang bukan dari keluarga besar.
\end{abstract}

Kata kunci: peran pola asuh; anak-anak; trauma perawatan; kakek-nenek

\begin{abstract}
Parenting is a group of parental attitudes that communicate to their children which creates an emotional atmosphere where parenting behavior is expressed. The active role of parents is a direct effort towards children and other important roles in creating the first social environment by children not to grandmothers and grandfathers. This study focuses on transferring the temporary role of childcare from parents to grandmothers and grandfathers and how grandparents care for children among working mothers. This study uses social action theory from Max Weber and Baumrind's parenting theory. The method of this research is qualitative, the informants in this study were nineteen family members with different family backgrounds. The location of the study was conducted in families who transferred caregiving roles to grandmothers and grandfathers in the city of Surabaya. The informant determination technique uses snowball technique. Methods of data collection in this study by indepth interviews and participating directly in the field. The result found in this study were the nineteen informant based on how the process of transferring childcare roles from parents to grandparents. Looking at the shifting factors of care, parents who are busy working, childcare by grandparents to their grandchildren is less assertive and always obeys the wishes of his grandchildren, the death of parents, discovered parents and the emergence of traumatized to the care of others who are not from large families.
\end{abstract}

Keywords: the role of parenting; children; trauma care; grandparents

\section{Pendahuluan}

Keluarga memiliki peran sebagai media sosialisasi pertama bagi anak. Keluarga merupakan kelompok sosial terkecil dalam masyarakat, dalam keluargalah semua aktivitas dimulai (Levin 1993; Bales \& Parsons 2014). Menurut Shochib (2000), keluarga merupakan suatu kesatuan sosial yang diikuti oleh hubungan darah antara satu dengan lainnya. Dalam pengertian psikologis yang dikemukakan oleh Soelaeman (Shochib 2000), keluarga adalah sekumpulan orang yang hidup bersama dalam tempat tinggal bersama dan masing-masing anggota merasakan adanya pertautan batin sehingga terjadi saling 
mempengaruhi, saling memperhatikan, dan saling menyerahkan diri. Sedangkan Dewantara (1962) menyatakan bahwa keluarga merupakan "pusat pendidikan yang pertama dan terpenting karena sejak timbulnya adab kemanusiaan sampai kini, keluarga selalu mempengaruhi pertumbuhan budi pekerti tiap-tiap manusia. Peran inilah yang membuat orangtua memiliki tanggung jawab terhadap perkembangan fisik dan mental seorang anak. Di keluargalah anak mulai dikenalkan terhadap ajaranajaran yang sesuai dengan kaidah-kaidah yang berlaku dalam agama maupun masyarakat.

Menurut Puji (2008), keluarga merupakan satu organisasi sosial yang paling penting dalam kelompok sosial dan keluarga merupakan lembaga di dalam masyarakat yang paling utama bertanggung jawab untuk menjamin kesejahteraan sosial dan kelestarian biologis anak manusia. Sedangkan menurut Rakhmat (1998), keharmonisan keluarga itu akan terwujud apabila masing-masing unsur dalam keluarga itu dapat berfungsi dan berperan sebagaimana mestinya dan tetap berpegangan teguh pada nilai-nilai agama kita, maka interaksi sosial yang harmonis antar unsur dalam keluarga itu akan dapat diciptakan.

Hal tersebut senada dengan pernyataan Aryatmi (dalam Kartono 1922) yang menyatakan bahwa keluarga adalah lingkungan hidup pertama dan utama bagi anak. Semua aktivitas anak dari mulai perilaku dan bahasa tidak terlepas dari perhatian dan binaan orangtua. Pola asuh orangtua yang penuh kasih sayang dan pendidikan tentang nilai-nilai kehidupan, baik agama maupun sosial budaya yang diberikan, merupakan faktor yang kondusif untuk mempersiapkan anak menjadi pribadi dan anggota masyarakat yang sehat.

Pola asuh merupakan pola pengasuhan yang berlaku dalam keluarga, interaksi antara orang tua dan anak selama mengadakan kegiatan pengasuhan (Tarmudji 2002). Lebih dari itu pola asuh ini akan membentuk watak dan karakter anak di masa dewasanya, karena tidak mungkin memahami orang dewasa tanpa ada informasi masa kanak-kanaknya karena masa itu adalah masa pembentukan (Bacon 1997). Hal tersebut kemudian diperkuat oleh pendapat Darling \& Steinberg (1993) mendefinisikan pola asuh sebagai kelompok sikap orangtua yang mengkomunikasikan kepada anaknya yang menciptakan suasana emosional dimana perilaku pengasuhan tersebut diekspresikan. Peran aktif orangtua adalah usaha langsung terhadap anak dan peran lain yang penting dalam menciptakan lingkungan sosial yang pertama oleh anak (Masruroh 2009).

Menurut Devi (2007) anak adalah titipan Tuhan Yang Maha Kuasa, karena itu nasib dan masa depan anak-anak adalah tanggung jawab kita semua. Tetapi tanggung jawab utama terletak pada orangtua masing-masing. Orangtualah yang pertama berkewajiban memelihara, mendidik, dan membesarkan anak-anaknya agar menjadi manusia yang berkemampuan dan berguna.

Menurut Puji (2008) pendidikan yang utama dan pertama bagi anak usia dini berada di rumah bersama orangtua (ayah dan ibu). Indikatornya adalah orangtua (ayah dan ibu) merupakan orang yang paling bertanggungjawab terhadap perkembangan anak-anaknya, orangtua (ayah dan ibu) merupakan orang yang pertama berinteraksi dengan anak-anaknya sebelum mereka berinteraksi dengan orang lain, lingkungan keluarga merupakan lingkungan terdekat yang sangat berpengaruh terhadap kepribadian anak, dan waktu yang dimiliki oleh anak lebih banyak dihabiskan di rumah bersama orang tua (Ayah dan Ibu).

Perubahan sosial yang terjadi pada era globalisasi, banyak ibu yang terlibat dalam aktivitas di sektor publik untuk membantu perekonomian keluarga, dan disibukkan dengan pekerjaan domestik kerumahtanggaan (Boushey 2009; Chesley 2017; Kahne 2019). Peran ganda yang dijalankan ibu dapat menimbulkan permasalahan pada pengasuhan anak. Pengasuhan erat kaitannya dengan kemampuan suatu keluarga atau rumah tangga dan komunitas dalam hal memberikan perhatian, waktu, dan dukungan untuk memenuhi kebutuhan fisik, mental, dan sosial anak-anak yang sedang dalam masa pertumbuhan serta bagi anggota keluarga lainnya (Latifah et al. 2007). Ada sekian banyak alasan mengapa ibu bekerja, mulai dari memenuhi kebutuhan ekonomi keluarga sampai sebagai suatu bentuk aktualisasi diri. Pro dan kontra fenomena ibu bekerja terus berlanjut. Ada pihak yang mengatakan ibu sebaiknya di rumah agar perkembangan anak lebih baik, tapi ada yang berpendapat bahwa dengan 
diam di rumah belum menjamin perkembangan anak menjadi lebih baik. Seiring dengan pro kontra ini banyak bermunculan hasil-hasil penelitian baik yang menentang maupun mendukung ibu bekerja (Itabiliana \& Hadiwidjojo 2013).

Pihak yang mendukung antara lain pada studi penelitian yang dilakukan Elizabeth Harvey, seorang psikolog peneliti di Universitas Massachusetts, di tahun 1999, mengungkapkan bahwa tidak ada dampak merugikan bagi anak-anak yang ibunya bekerja. Kemudian penelitian yang dilakukan oleh sebuah tim dari Universitas Texas tahun 2005, tidak menemukan adanya masalah perkembangan pada anak-anak yang ibunya bekerja di luar rumah. Penelitian ini mengungkapkan bahwa ibu memang sumber penting dari pengasuhan anak tapi dia tidak harus tinggal di rumah selama 24 jam penuh untuk membangun kedekatan dengan anak (Itabiliana \& Hadiwidjojo 2013).

Sedangkan pihak yang tidak mendukung antara lain pada suatu penelitian yang dilakukan Bio-medical Library di Universitas Minnesota pada tahun 2001, menunjukkan bahwa anak-anak dari ibu yang bekerja di luar rumah selama 30 jam atau lebih dalam seminggu mengalami keterlambatan perkembangan moral. Penanaman nilai-nilai moral sangat dibutuhkan untuk mengoptimalkan perkembangan kecerdasan moral mereka. konsep kecerdasan moral anak usia prasekolah perlu dipahami dan dikaji lebih dalam agar menjadi bahan masukan bagi orangtua, pendidik/guru atau orang dewasa lainnya untuk dapat dilakukan pengembangan kecerdasan moral sejak dini (Gunarsa 2004).

Pergeseran perempuan dari seorang ibu rumah tangga dan seorang istri menjadi perempuan bekerja menjadikan banyak keluarga dewasa ini mempunyai "dual career". Tuntutan pekerjaan berhubungan dengan tekanan yang berasal dari beban kerja yang berlebihan dan waktu, seperti pekerjaan yang harus diselesaikan terburu-buru dan deadline. Tuntutan keluarga berhubungan dengan waktu yang dibutuhkan untuk menangani tugas-tugas rumah tangga dan menjaga anak ditentukan oleh besarnya keluarga, komposisi keluarga dan jumlah anggota keluarga yang memiliki ketergantungan terhadap anggota lain (Yang et al. 2000). Akibatnya, seorang ibu sulit membagi tenaga antara pekerjaan di rumah dan pekerjaan di luar rumah, lebih-lebih kalau ada pula anak yang perlu mendapat perhatian khusus dari keluarganya (Latif 2001).

Kodrat sebagai perempuan memang tidak bisa dipisahkan. Kehilangan waktu bersama anak untuk bekerja merupakan salah satu dilematika yang dihadapi. Pengasuhan orang tua tersebut akan tergantikan dengan pengasuhan oleh kakek atau nenek, sehingga akan memungkinkan adanya jarak antara orangtua dengan anak (Bowers \& Myers, 1999; Musil et al. 2011). Penurunan kualitas pola asuh dalam keluarga inilah yang menyebabkan kondisi keluarga yang kurang harmonis. Selain itu , keadaan yang kurang harmonis di keluarga ini juga berasal dari ketidakmampuan dalam pemenuhan peran sebagai pasangan suami istri dan peran sebagai orang tua akibat terlalu sibuk dan lelah dalam pekerjaannya. Jika ibu yang bekerja tersebut tidak dapat menyeimbangkan antara pekerjaan dan keluarga maka akan menimbulkan suatu tekanan sehingga mengakibatkan ibu tersebut sering marahmarah kepada anak dan suami, kurang memperhatikan anak-anak dan suami, cepat lelah, dan lain-lain.

\section{Metode Penelitian}

Tipe penelitian yang digunakan oleh peneliti yaitu tipe kualitatif dengan menggunakan pendekatan berperspektif konstruktivisme. Tipe penelitian kualitatif digunakan untuk mencari jawaban mengenai masalah yang dicari sehingga akan ditemukan jawaban yang sejelas-jelasnya dari informan dan memperoleh gambaran yang nyata mengenai suatu kejadian menurut pandangan informan yang diteliti. Teknik penentuan informan dalam penelitian ini yaitu peneliti menggunakan teknik Snowball untuk mendapatkan informan yang dirasa tepat untuk menjawab dan memiliki wawasan yang luas mengenai permasalahan penelitian tersebut.

Dalam penelitian ini, kriteria yang harus dipenuhi sehingga dapat menjadi informan yang dapat diwawancara, yaitu seorang orang tua yang bekerja dan menitipkan anaknya pada nenek dan kakek. Sedangkan untuk pengumpulan data dalam penelitian ini yaitu dilakukan wawancara mendalam 
(indepth interview) dengan menggunakan pedoman wawancara agar dapat memperoleh data secara lebih rinci yang berkaitan dengan topik penelitian.

\section{Hasil dan Pembahasan}

\section{Pengalihan peran pengasuhan anak dari orang tua ke nenek dan kakek}

Pada proses pengalihan peran sementara pengasuhan anak dari orang tua ke nenek dan kakek yang hendak disampaikan oleh orang tua dan nenek dan kakek pada keluarga yang suami dan istri bekerja. Peningkatan keterlibatan perempuan dalam berbagai kegiatan ekonomi disebabkan oleh berbagai faktor antara lain karena didorong oleh tekanan ekonomi keluarga dan tekanan ekonomi pasar yang mengubah tatanan sosial ekonomi terutama menyangkut nilai barang dan uang dalam suatu masyarakat (Abdullah 2001).

Selain itu, perkembangan dan pertumbuhan ekonomi terjadi dengan sangat pesat. Hal ini mendorong perempuan untuk ikut serta dalam pemenuhan kebutuhan rumah tangga. Dalam era sekarang, di mana ilmu dan teknologi berkembang dengan pesat, menyebabkan semakin terkikisnya sekat-sekat yang memisahkan antara pria dan perempuan untuk bekerja. Tergantinya peran orang tua dalam mengasuh anak-anak mereka diperkuat apabila kedua orang tua mereka berada jauh dengan anaknya dan memiliki kesibukan pekerjaan (Woodworth 1994). Pengasuhan erat kaitannya dengan kemampuan suatu keluarga atau rumah tangga dan komunitas dalam hal memberikan perhatian, waktu, dan dukungan untuk memenuhi kebutuhan fisik, mental dan sosial anak-anak yang sedang dalam masa pertumbuhan serta bagi anggota keluarga lainnya.

Perempuan sebagai ibu rumah tangga dalam keluarga mempunyai pengaruh yang sangat besar terhadap kelestarian suasana rumah tangga, keharmonisan keluarga serta kesejahteraan keluarga. Sesuai dengan kedudukannya, perempuan berkewajiban memainkan beberapa fungsi dan peranan secara bersama-sama, seperti sebagai istri, sebagai partner sexual, sebagai pengatur rumah tangga, sebagai ibu dari anak-anak dan pendidik, dan sebagai makhluk sosial yang ingin berpartisipasi aktif dalam lingkungan sosial. Semakin mantap perempuan itu memainkan berbagai peranannya sebagaimana diatas, akan semakin positif dan produktiflah dirinya.

Peran pokok seorang ibu adalah mengurus rumah tangga, tetapi seiring dengan makin terbukanya kesempatan menuntut pendidikan, maka semakin terbukalah kesempatan untuk ke lapangan pekerjaan. Perempuan yang bekerja di luar rumah, fungsi manifestnya adalah meningkatkan kesejahteraan ekonomi keluarganya untuk memenuhi kebutuhan hidupnya. Dengan demikian berkurangnya waktu pengasuhan anak oleh orang tua memungkinkan terjadinya perubahan pola, peran serta fungsi pada pengasuhan anak.

Seorang anak dalam pengasuhan nenek dengan berbagai pengalaman masa lalu kedua orang tuanya akan membentuk karakter kepribadian yang khas, seperti data yang ditemukan di lapangan bahwa anak-anak yang diasuh oleh nenek dan kakek hingga keluarga besar karena para orang tua sibuk dengan pekerjannya ada kecenderungan jiwa mandiri. Jiwa mandiri berdasarkan data yang ditemukan di lapangan akan terlihat pada anak-anak yang tidak diasuh oleh orang tuanya, mereka terbiasa melakukan sesuatu dengan kemampuannya sendiri. Rasa bertanggung jawab sudah tertanam dalam diri anak-anak yang tidak asuh orang tuanya, mereka belajar membagi waktunya untuk bermain, belajar dan mengerjakan pekerjaan rumah (Rodgers \& Jones 1999; Gibson 2002).

Keluarga merupakan sumber utama dan pertama dalam proses penanaman nilai dan norma. Penanaman ini dilakukan lewat interaksi sosial, dalam interaksi ini kemudian terjadi proses internalisasi. Ada beberapa faktor yang memberikan pengaruh terhadap seseorang dari hasil interaksi sosial yaitu imitasi adalah kecenderungan untuk meniru merupakan naluri yang mempunyai peranan penting dalam interaksi sosial dan ajaran yang tepat membuat seorang anak menjadi paham dengan akan kemandiriannya dan rasa tanggung jawab. Pengasuhan nenek mendapatkan support atau dukungan dari cucunya sehingga nenek merasa nyaman dekat dengan cucunya (Kornhaber \& 
Woodward 1981). Hal ini nampak ketika nenek tersebut sering bercerita mengenai pengalaman hidupnya kepada cucunya. Cucu mereka mendengarkan cerita nenek dengan penuh perhatian dan seksama sehingga nenek merasa nyaman untuk bercerita dengan cucunya. Ekspresi mengerti yang diperlihatkan oleh cucunya merupakan bentuk dukungan pada nenek mereka. Hal ini terjadi hubungan timbal balik antara nenek kepada cucunya.

Dampak negatif pengasuhan kakek dan nenek. Kasih sayang seorang nenek terhadap cucunya terkadang lebih besar dari pada kepada cucunya. Perhatian yang besar tercurah kepada cucunya dengan keterbatasan kemampuannya, hal ini terkadang berdampak negatif pada anak (Gibson 1999; Hayslip et al. 2002; Edwards 2003). Anak akan bertindak semaunya dan sulit untuk diarahkan. Masa anak-anak merupakan masa perkembangan emosionalitas yang lebih tinggi, keinginan mereka harus bisa dicapai dengan memaksa kedua orang tuanya untuk mendapatkannya.

Bentuk dan cara orang tua itu memberikan kasih sayang kepada anak berbeda-beda, ini dipengaruhi oleh latar belakang lingkungan pendidikan dan kondisi kehidupan pribadi orang tua. Begitu juga anak yang tinggal di lingkungan yang keras akan mendorong anak untuk berperilaku agresif. Masa anakanak merupakan masa dimana mereka mendapatkan pendidikan dan pembinaan moral. Pendidikan dini ditanamkan oleh keluarga terdekat dimana anak tersebut dilahirkan dan dibesarkan. Anak-anak yang diasuh oleh kakek dan nenek dalam pendidikan formal pada umumnya didapatkan oleh anak di sekolah namun demikian peranan keluarga sangat besar dalam meningkatkan prestasi belajar anak (Berrick 1994). Pilar pendidikan terdiri dari tiga komponen yaitu guru, orang tua, dan masyarakat sebagai pengontrol dari berjalannya sistem pendidikan tersebut.

\section{Simpulan}

Dari penelitian ini dapat disimpulkan bahwasannya pengalihan peran pengasuhan anak dari orang tua ke nenek dan kakek dikarenakan beberapa faktor yaitu; (1) peran orang tua untuk memberikan pengasuhan ataupun peran sebagai keluarga yang mengalami perubahan saat mengalami; (2) pengasuhan yang dilakukan kakek dan nenek kepada cucunya kurang memberikan aturan-aturan yang tegas dan selalu menuruti keinginan cucunya; (3) munculnya ketraumaan terhadap pengasuhan orang lain yang bukan dari keluarga besar; (4) orang tua yang sibuk bekerja, pengasuhan anak oleh nenek dan kakek hanya sebatas mengawasi atau menjaga anak-anak ketika kedua orang tuanya sedang tidak ada dirumah. Hal ini berdasarkan data peneliti dilapangan dan proses wawancara secara mendalam; (5) meninggalnya salah satu orang tua ayah ataupun ibu sehingga menyebabkan adanya orang tua tunggal, sehingga kakek dan nenek ikut membantu dalam pengasuhan cucunya; (6) orang tua yang telah bercerai cenderung melepaskan tanggung jawabnya terhadap anak sehingga nenek dan kakek akan mengambil alih tanggung jawab pengasuhan anak dan juga membiayai kehidupan anak tersebut.

\section{Daftar Pustaka}

Bales RF \& Parsons T (2014) Family: Socialization and Interaction Process. Routledge.

Baumrind D (1991) The influence of parenting style on adolescent competence and subtance use. Journal of Early Adolescence 11 (1):56-95.

Berrick JD, Barth RP \& Needell B (1994) A comparison of kinship foster homes and foster family homes: implications for kinship foster care as family preservation. Children and Youth Services Review 16:33- 63.

Boushey H (2009) The new breadwinners. The Shriver Report: A Woman Nation Changes Everything:158-64.

Bowers B, Myers B (1999) Grandmothers providing care for grandchildren: Consequences of Various Levels of Caregiving. Family Relations, 48(3), 303-311. doi:10.2307/585641

Chesley N (2017) What does it mean to be a "breadwinner" mother? Journal of Family Issues 38 (18):2594-2619.

Edwards OW (2003) Living with grandma. School Psychology International 24 (2):204217. doi:10.1177/0143034303024002005

Gibson PA (1999) African American grandmothers: New mothers again. Affilia 14 (3):329-343. 
Gibson PA (2002) African American grandmothers as caregivers: Answering the call to help their grandchildren. Families in Society 83 (1):35-43.

Hayslip JB, Emick MA, Henderson CE \& Elias K (2002) Temporal variations in the experience of custodial grandparenting: A short-term longitudinal study. Journal of Applied gerontology 21 (2):139-156.

Itabiliana VK \& Hadiwidjojo P (2013) Problematika Ibu yang Bekerja. Dalam http://ekonomi.kompasiana.com/bisnis/2013/04/29/problematika-ibu-yang-bekerja555820.html. Diakses pada 31 maret 2017.

Kahne H (2019) Women's Work and Women's Lives: The Continuing Struggle Worldwide. Routledge.

Kornhaber A \& Woodward K (1981) Grandparents/Grandchildren: The Vital Connection. Garden City, NY: Anchor Press/Doubleday.

Latifah M, Alfiasari \& Hernawati N (2007) Kualitas tumbuh kembang, pengasuhan orang tua, dan faktor risiko komunitas pada anak usia prasekolah wilayah pedesaan di Bogor. dalam http://repository.ipb.ac.id//jurnal/keluarga\%20volume.pdf. Diakses pada 17 januari 2018.

Levin I (1993) Family as mapped realities. Journal of Family Issues 14 (1):82-91.

Musil CM, Gordon NL, Warner CB, Zauszniewski JA, Standing T \& Wykle M (2011) Grandmothers and caregiving to grandchildren: Continuity, change, and outcomes over 24 months. The Gerontologist 51 (1):86-100.

Rodgers AY \& Jones RL (1999) Grandmothers who are caregivers: An overlooked population. Child and Adolescent Social Work Journal 16 (6):455-466.

Shochib M (2000) Pola Asuh Orang Tua dalam Membantu Anak Mengembangkan Disiplin Diri. Jakarta: Rineka Cipta.

Tarmudji T (2002) Hubungan pola asuh orang tua dengan agresivitas remaja. Jurnal Pendidikan dan Kebudayaan 8 (37):504-519.

Woodworth R (1994) Grandparent-Headed Households and Their Grandchildren: A Special Report. Washington, DC: AARP Grandparent Information Center. 